\title{
Encapsulation of Blackberry Anthocyanins by Thermal Gelation of Curdlan
}

\author{
Daniela S. Ferreira, Adelia F. Faria, Carlos R. F. Grosso \\ and Adriana Z. Mercadante* \\ Faculdade de Engenharia de Alimentos, Universidade Estadual de Campinas, \\ CP 6121, 13083-862 Campinas-SP, Brazil
}

\begin{abstract}
As amoras-pretas apresentam coloração atrativa devido à presença de antocianinas, porém a utilização destes pigmentos como corante natural é difícil, pois alguns fatores, especialmente $\mathrm{pH}>3$, provocam sua descoloração. Por outro lado, a microencapsulação tem sido utilizada na indústria para proteger ingredientes ativos. Os objetivos deste estudo foram estabelecer as condições de encapsulação de antocianinas de amora-preta, avaliar as características das cápsulas, bem como a liberação de antocianinas. Três polissacarídeos (curdlana, pectina e alginato de sódio) foram avaliados como material de parede para obter cápsulas por gelificação. A curdlana foi escolhida, pois foi a única goma capaz de formar um gel firme sob baixo $\mathrm{pH}$. As cápsulas apresentaram forma esférica e multinucleada, e a eficiência de encapsulação variou entre 80,3 e 96,7\%. As curvas de liberação apresentaram comportamento cinético de primeira ordem, com forte efeito "burst" com 80 a 100\% das antocianinas liberadas em solução pH 1 após 20 min.
\end{abstract}

Blackberry shows an attractive color due to the presence of anthocyanins; however the use of these pigments as natural colorant is difficult since some external agents, specially $\mathrm{pH}>3$, cause their discoloration. On the other hand, encapsulation techniques have been widely used in the industry to protect active ingredients. The aims of this study were to establish the encapsulation conditions of anthocyanins from blackberry, to evaluate the capsules characteristics, as well as the anthocyanins release. Three polysaccharides (curdlan, pectin and sodium alginate) were evaluated as wall material to obtain capsules by gelation. Curdlan was chosen since it was the only gum capable to form hard gel under low $\mathrm{pH}$ value. The capsules showed spherical form and multinucleated appearance, and encapsulation efficiency ranged from 80.3 to $96.7 \%$. The release curves followed first order kinetics, with a strong burst effect, 80 to $100 \%$ of the anthocyanins released in solution at $\mathrm{pH} 1$ after $20 \mathrm{~min}$.

Keywords: anthocyanins, encapsulation, HPLC-PDA-MS/MS, release curve, Rubus spp

\section{Introduction}

The blackberry belongs to the ROSACEAE family, Rubus genus, and these fruits show attractive color characteristics and beneficial properties, such as antioxidant activity due to the high content of anthocyanins. ${ }^{1}$ In Brazil, the first plants were introduced in 1972 by the Empresa Brasileira de Pesquisa Agropecuária (Embrapa) in Rio Grande do Sul State, located in the South region. From foreign cultivars, mainly Brazos, Comanche and Cherokee, from the University of Arkansas State (United States), Embrapa developed cultivars adapted to the Brazilian geographical conditions and consumers demand, such as

*e-mail: azm@fea.unicamp.br cultivar Ébano introduced in 1981, and afterwards cultivars Negrita (1983), Tupy and Guarani (1988), and Caingangue (1992) were developed. Currently in Brazil, the most commercialized cultivar is the Tupy, followed by cultivars Guarani and Brazos, all being hybrid species. ${ }^{2}$

Independently of the cultivar or country, the major anthocyanins found in the blackberry (Rubus spp.) were cyanidin 3-glucoside (77.0-92.8\%), cyanidin 3-rutinoside (0.6-4.6\%), cyanidin 3-xyloside $(0.3-7.7 \%)$, cyanidin 3-malonyl-glucoside (1.5-3.9\%), and cyanidin 3-dioxalylglucoside (1.5-14.9\%)., ${ }^{3,4}$ In addition, Wu and Prior $^{5}$ also identified these five anthocyanins in blackberry from unidentified cultivars from the United States, along with other three different anthocyanins, cyanidin 3-arabinoside, pelargonidin 3-glucoside, and peonidin 3-glucoside. The 
structures of these anthocyanins are illustrated in Figure 1. On the other hand, the anthocyanin contents of blackberry fruits, expressed as cyanidin 3-glucoside, showed a large variation, from 67.4 to $248.0 \mathrm{mg}$ per $100 \mathrm{~g}$, in 19 cultivars from several countries in North and South America and Europe. ${ }^{3,6}$

Anthocyanins would be the ideal substitutes for artificial red colorants because of their bright colors varying from red to blue, water solubility and non-toxicity. Nevertheless, the use of these pigments in foods has been hampered by their poor stability that is affected by physical and chemical factors as temperature, $\mathrm{pH}$, light, solvent and the structure of the pigment itself. ${ }^{7}$ In fact, the cation flavylium, the colored anthocyanin form, is only predominant at $\mathrm{pH}$ values lower than $3 .^{8}$

Microencapsulation can be an interesting alternative for the replacement of the artificial colorants by anthocyanins in the food and pharmaceutical industry, acting as a protector coat against ambient adverse conditions, such as light, humidity, oxygen, to avoid interactions with other compounds and to make easier to handle the bioactive compound. These small capsules are indiscriminately called particles, capsules or spheres, and according to their size, the prefix nano $(<50 \mathrm{~nm})$ or micro $(50 \mathrm{~nm}-2 \mathrm{~mm})$ is incorporated. ${ }^{9}$

Alginate and pectin are the most used polysaccharides that form gel in the presence of ions. Alginates are high molecular weight polymers with a degree of polymerization (DP) in the range of 17600-528000, molecular weight (MW) of 20000-600000, where the building blocks of alginic acid are $\beta$-D-manuronic acid and its C-5 epimer, $\alpha$-L-guluronic acid, linked by $(1 \rightarrow 4)$-glycosidic bonds to form linear molecules. Pectic substances are formed by D-galacturonic acid with different esterification degree, linked by $(1 \rightarrow 4)$-glycosidic bonds with MW of approximately $11000-150000 .{ }^{10}$ Another interesting gelifying material is curdlan, an extracellular bacterial high molecular weight polysaccharide produced by Alcaligenes faecalis var. myxogenes, and exclusively composed by $(1 \rightarrow 3)-\beta$-D-glucans. ${ }^{11}$ One of the unique features of curdlan is that aqueous suspensions can be thermally induced to produce high-set gels, which do not return to the liquid state upon heating. ${ }^{12}$

Encapsulation of anthocyanins by thermal gelation was investigated in a study using glucan. ${ }^{13}$ In addition, the stability of natural anthocyanins toward alkaline environment and visible light irradiation was enhanced by intercalation into montmorillonite, a clay mineral. ${ }^{14}$ Considering the blackberry extract potentialities and the red attractive coloration of the anthocyanin at low $\mathrm{pH}$, the objectives of this study were to choose among three polysaccharides the best wall material for gelation at low $\mathrm{pH}$ value, evaluate some parameters used for thermal gelation of curdlan, verify the effect of the thermal gelation process on the anthocyanin composition, as well as to characterize the anthocyanin capsules, and determine the anthocyanin release profile.

\section{Experimental}

\section{Materials}

The following polysaccharides were used: sodium alginate from Manugel DMB (San Diego, USA) batch 500771 and ref. 669990 with high molecular weight and high guluronate group content; citric pectin with low methoxylation degree (26-30\%), type 8002/R with amidation degree of 15-21\%, batch 11655 and ref. 11.9900 (Citrus Colloids S/A, donated by Ind. Braspectin S.A., Limeira, Brazil); and curdlan gum (ref. 54724-00-4) with moisture content no more than $10 \%\left(60^{\circ} \mathrm{C}\right.$, vacuum, $\left.5 \mathrm{~h}\right)$ donated by Takeda Chemical Industries Ltd. (Osaka, Japan).

Frozen blackberry fruits (Rubus spp.), $8 \mathrm{~kg}$, Tupy cultivar, were acquired from DeMarchi (Jundiaí, Brazil). The content of monomeric anthocyanins, expressed as cyanidin 3-glucoside, was about $104 \mathrm{mg}$ per $100 \mathrm{~g}$ in these fruits.

Standards of cyanidin 3-glucoside, cyanidin 3-galactoside, cyanidin 3-rutinoside, cyanidin 3,5-diglucoside, cyanidin 3 -rhamnoside, pelargonidin 3-glucoside, peonidin<smiles>[R]Oc1cc2c(O)cc(O)cc2[o+]c1-c1ccc(O)c([R])c1</smiles>

Figure 1. Chemical structures of blackberry anthocyanins.

\begin{tabular}{c|cc} 
Compounds & $\mathrm{R}^{1}$ & $\mathrm{R}^{2}$ \\
\hline cyanidin 3-glucoside & $\mathrm{OH}$ & glucose \\
cyanidin 3-rutinoside & $\mathrm{OH}$ & rutinose \\
cyanidin 3-xyloside & $\mathrm{OH}$ & xylose \\
cyanidin 3-malonyl-glucoside & $\mathrm{OH}$ & malonyl-glucose \\
cyanidin 3-dioxalyl-glucoside & $\mathrm{OH}$ & dioxalyl-glucose \\
cyanidin 3-arabinoside & $\mathrm{OH}$ & arabinose \\
pelargonidin 3-glucoside & $\mathrm{H}$ & glucose \\
peonidin 3-glucoside & $\mathrm{OCH}_{3}$ & glucose
\end{tabular}


3-glucoside, cyanidin and pelargonidin were obtained from Extrasynthèse (Genay, France).

\section{Evaluation of gelling power of different polysaccharides}

In order to find a wall material that is able to form a hard gel at $\mathrm{pH}<2.5$, which is the condition where anthocyanins keep their colored form, three polysaccharides at three different concentrations were tested for their gelling power. Alginate, pectin and curdlan were added at 2, 5 and $6 \%(\mathrm{~m} / \mathrm{v})$ concentrations in aqueous solutions of citric acid at $\mathrm{pH}$ values of 1.5, 2.0 and 2.5. The aqueous solutions of polysaccharides were heated until their complete dissolution $\left(\mathrm{T}<40^{\circ} \mathrm{C}\right)$. For alginate and pectin gelling, a $2 \%$ calcium chloride solution was added to the polysaccharide solution, getting a final salt concentration of $1 \%$. For curdlan gelling, the polysaccharide solution was heated at $c a .80^{\circ} \mathrm{C}$. Visual observation was carried out based on the polysaccharide capacity to change from the sol to gel state.

\section{Preparation of the anthocyanin extract}

The anthocyanin extract was obtained from $400 \mathrm{~g}$ of homogenized frozen blackberries. The extraction was carried out with methanolic solution containing $1 \% \mathrm{HCl}$ in a homogenizer (Metabo, Nurtingen, Germany) at room temperature. ${ }^{15}$ This suspension was filtered and washed, using the extractor solution. The extract was concentrated in a rotary evaporator $\left(\mathrm{T}<38^{\circ} \mathrm{C}\right)$ for methanol evaporation and this concentrated crude aqueous anthocyanin extract was kept under nitrogen (99\% purity) at $-36{ }^{\circ} \mathrm{C}$ until capsule preparation.

\section{Production of curdlan capsules containing blackberry anthocyanin extract}

The following variables were evaluated for the encapsulation process of anthocyanins: three different concentrations of curdlan aqueous solutions, curdlananthocyanin solution at temperatures of 35,40 and $45^{\circ} \mathrm{C}$, oil bath temperature of 70,80 and $90{ }^{\circ} \mathrm{C}$, oil level at 5 and $6 \mathrm{~cm}$; and height between oil surface and atomizer of 4,5 and $11 \mathrm{~cm}$. After these initial tests, $5 \mathrm{~mL}$ of the concentrated crude anthocyanin extract, containing $2.08 \mathrm{mg}$ of anthocyanins $\mathrm{mL}^{-1}$, were added to $30 \mathrm{~mL}$ of the curdlan solutions, resulting in polysaccharide final concentrations of $4.3,5.1$ and $5.6 \%(\mathrm{~m} / \mathrm{v})$. The curdlan-anthocyanin solution was sprayed into the soybean oil bath, which was under constant temperature and slow agitation, using a double fluid atomizer at $40{ }^{\circ} \mathrm{C}$, diameter of $1 \mathrm{~mm}$ and air pressure of $4.90 \mathrm{kPa}$. The capsules were recovered by filtration under vacuum, washed once with chloroform and residual solvent were removed under a slow nitrogen flow.

Immediately after capsules preparation, moisture, anthocyanin content, capsules morphology and core release were evaluated. All analyses were carried out in triplicate. In addition, the effect of encapsulation by gelation on the anthocyanin profile was evaluated by high performance liquid chromatography connected to diode array and mass spectrometer detectors (HPLC-PDA-MS/MS).

\section{Analysis of anthocyanins by HPLC-PDA-MS/MS}

In order to remove sugars, the concentrated crude extract $(15 \mathrm{~g})$ was submitted to open column chromatography on XAD-7 before the HPLC-PDA-MS/MS analysis. ${ }^{16,17}$ The partially purified extract was diluted in 5\% formic acid/ methanol (85:15) immediately before analysis by HPLCPDA-MS/MS. The extract was analyzed on a Shimadzu (Kyoto, Japan) HPLC, equipped with quaternary pumps (model LC-20AD), on line degasser and a Rheodyne injection valve with $20 \mu \mathrm{L}$ loop, connected in series to a PDA detector (Shimadzu, model SPD-M20A) and a mass spectrometer with an ion-trap analyzer from Bruker Daltonics (model Esquire 4000, Bremen, Germany). The anthocyanins were separated as previously described, ${ }^{16}$ on $\mathrm{a}_{18}$ Shim-pack CLC-ODS column (Shimadzu, Canby, OR, USA), using as mobile phase a linear gradient of 5\% formic acid/methanol (v/v) from 85:15 to 20:80 in $25 \mathrm{~min}$, the latter proportion being maintained for further $15 \mathrm{~min}$, at a flow rate of $0.9 \mathrm{~mL} \mathrm{~min}^{-1}$ and column temperature set at $26^{\circ} \mathrm{C}$. The UV-Visible spectra were obtained between 250 and $600 \mathrm{~nm}$ and the chromatograms were processed at 280 and $520 \mathrm{~nm}$. After passing through the flow cell of the PDA, the column eluate was split allowing only $0.15 \mathrm{~mL} \mathrm{~min}^{-1}$ into the electrospray ionization (ESI) interface. The MS/MS parameters were set as previously reported. ${ }^{16}$ The anthocyanins were identified based on the combined information provided by elution order in the reversed phase column, co-chromatography with standards, UV-Visible and mass spectra characteristics compared to the literature data. ${ }^{5,16,18}$

\section{Characterization of curdlan capsules}

For moisture determination, $3 \mathrm{~g}$ of capsules were weighed in three Petri plates and these plates were kept into an oven at $60{ }^{\circ} \mathrm{C}$ at atmospheric pressure until constant weight.

The extraction of surface anthocyanins from the capsules was carried out by quickly washing with $1 \%$ $\mathrm{HCl}$ methanol solution under vacuum, whereas the total 
anthocyanins were obtained by capsule maceration with the same solvent, using pestle and mortar. Quantification was carried out by the differential $\mathrm{pH}$ method, ${ }^{19}$ using an Agilent 8453 spectrophotometer (Santa Clara, USA), and the results were expressed as cyanidin 3-glucoside.

Encapsulation efficiency (\%EE) was calculated according to equation $1,{ }^{20}$ using the results from total (TAC) and surface anthocyanin (SAC) contents.

$\% \mathrm{EE}=\frac{(\mathrm{TAC}-\mathrm{SAC})}{\mathrm{TAC}} \times 100$

An optical stereo-microscope (Citoval 2 model, Carl Zeiss, Jena, Germany) was used to observe the general morphology of the capsules, using objectives from $1.5 \times$ to $3.5 \times$. The images were registered and saved by the Global Lab Image software from Data Translation (Marlborough, USA). Using the microscope images, the size distribution and mean size were calculated by measuring 100 to 300 capsules.

\section{Release curves determination}

Glass tubes were prepared with $1 \mathrm{~g}$ of capsules and $10 \mathrm{~mL}$ of $0.025 \mathrm{~mol} \mathrm{~L}^{-1}$ potassium chloride buffer solution at $\mathrm{pH} 1.0$, and submitted to constant shaking at $22 \mathrm{rpm}$ in a rotary tube shaker (blood homogenizer model AP22, Phoenix, Araraquara, Brazil) in the dark. The total anthocyanin content was obtained by capsules maceration using buffer solution $\mathrm{pH} 1$. The anthocyanin release was monitored by measuring the solution absorbance at $510 \mathrm{~nm}$, each 10 min during $3 \mathrm{~h}$. Three different individual tubes were mixed at each time.

The anthocyanin contents in $\mu \mathrm{mol} \mathrm{L} \mathrm{L}^{-1}$ were calculated according to the Beer`s Law, using the major anthocyanin (cyanidin 3-glucoside) absortivity of $26900 \mathrm{~L} \mathrm{~mol}^{-1} \mathrm{~cm}^{-1}$ in buffer solution at $\mathrm{pH} 1.0 .^{21}$ The release curve was calculated as percentage of the released anthocyanin contents related to the total anthocyanin one.

\section{Kinetic analysis}

The data were fitted by using Microcal Origin ${ }^{\mathrm{TM}} 7.0$ (OriginLab Corporation, Northampton, USA).

\section{Results and Discussion}

\section{Choice of the wall material and conditions for thermal gelation of curdlan}

For all concentrations, at $\mathrm{pH}$ values of 1.5 and 2.0, both pectin and alginate precipitated due to the protonation of their carboxylic acid groups, ${ }^{22}$ whilst at $\mathrm{pH} 2.5$ these polysaccharides formed a weak gel.

On the other hand, curdlan, at all concentrations ( 2 to $6 \%$ ) and at all $\mathrm{pH}$ values (1.5 to 2.5), dissolved in water at the expected temperature of $c a .40^{\circ} \mathrm{C}$, as well as formed gel at $c a .80^{\circ} \mathrm{C}$, as previously reported. ${ }^{23}$ However, with $2 \%$ of curdlan, the gel formed was weak and, thus, not suitable for capsules preparation.

After visual observation of the polysaccharides gelling power, curdlan was chosen as the wall material, because among the tested polymers, curdlan was the only one that did not loose gelling capacity at $\mathrm{pH}$ lower than 2 , being able to form a hard gel.

The variation on the thermal gelation process conditions was carried out in order to obtain curdlan-anthocyanin capsules with good physical characteristics, such as size distribution and morphology, as well as, to minimize losses of either core or wall material, during the process.

When higher temperatures for both the curdlananthocyanin solution $\left(45^{\circ} \mathrm{C}\right)$ and oil bath $\left(90^{\circ} \mathrm{C}\right)$ were used in the encapsulation process, the solution viscosity was too high for the atomizer and anthocyanin degradation could occur, while when lower oil bath temperature $\left(70{ }^{\circ} \mathrm{C}\right)$ was applied, curdlan did not form the stable and thermo-irreversible gel, the so called high-set gel with triple helical conformation. ${ }^{12,24}$ In addition, curdlan was not completely dissolved when curdlananthocyanin solution was kept at $35^{\circ} \mathrm{C}$.

Both the level of oil bath and the height from atomizer to oil surface were established in order to minimize the losses of formed capsules. It is important to note that these parameters values have strong influence on the capsule size features. When $6 \mathrm{~cm}$ of oil bath was used, bath shaking was not strong enough, resulting in agglomerates or deformed large capsules, while at the chosen level $(5 \mathrm{~cm})$, the shaking was more uniform, allowing the dispersion of the capsules in the oil bath, and thus formation of round capsules. Heights from atomizer to oil surface higher than $4 \mathrm{~cm}$ resulted in loss of curdlan-anthocyanin solution, which deposited itself on the recipient walls, and few capsules were formed. Since the hydration pK between the flavylium cation and hemiketal forms of cyanidin 3-glucoside was 3.0, ${ }^{4}$ the chosen $\mathrm{pH}$ of 1.5 assured that the colored flavylium cation was the predominant form in the blackberry anthocyanin extract.

Considering these facts, some suitable conditions for curdlan-anthocyanin capsules preparation, using different curdlan concentrations, were established as follows: temperature of curdlan-anthocyanin solution at $40^{\circ} \mathrm{C}, \mathrm{pH}$ of curdlan-anthocyanin solution at 1.5 , temperature of oil bath at $80^{\circ} \mathrm{C}$, level of oil bath was $5 \mathrm{~cm}$, and height from atomizer to oil surface was $4 \mathrm{~cm}$. 

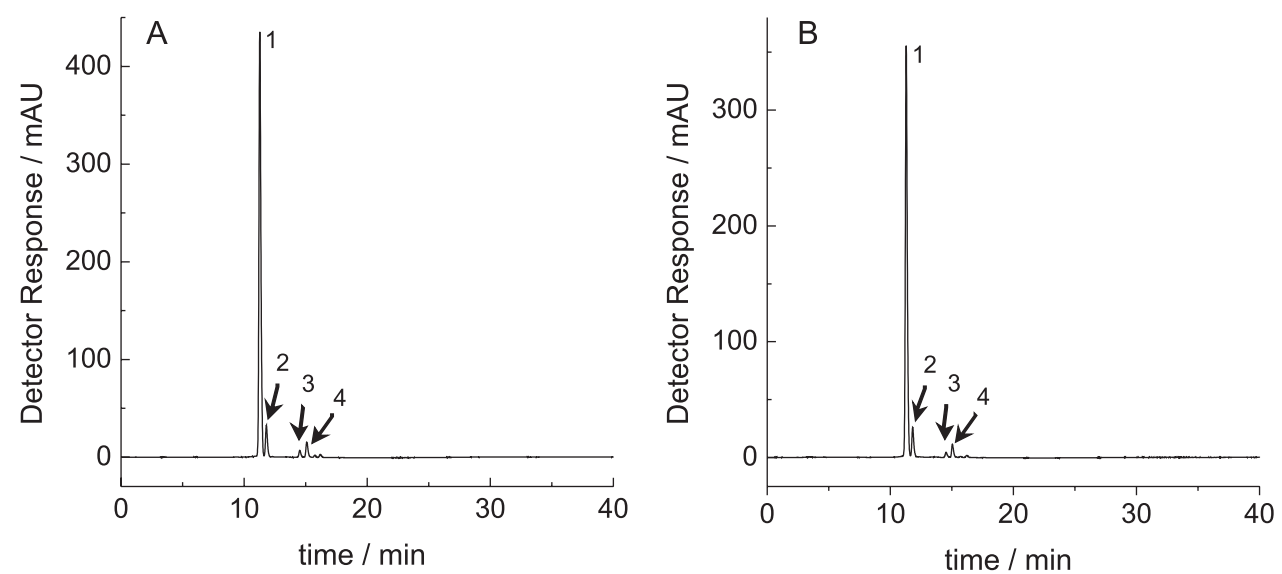

Figure 2. Anthocyanin profiles (A) before and (B) after the encapsulation process. Chromatographic conditions: see text. Both processed at $520 \mathrm{~nm}$. The peak identification is given in Table 1 .

Table 1. Chromatographic, UV-Vis and mass spectrometry characteristics of anthocyanins from blackberry, and composition before and after encapsulation

\begin{tabular}{|c|c|c|c|c|c|c|}
\hline \multirow[t]{2}{*}{ Peak $^{\mathrm{a}}$} & \multirow[t]{2}{*}{ Compounds } & \multirow{2}{*}{$\mathrm{t}_{\mathrm{R}}(\min )$} & \multirow[t]{2}{*}{$\lambda_{\max }^{\mathrm{b}}(\mathrm{nm})$} & \multirow[t]{2}{*}{ MS/MS $(m / z)$} & \multicolumn{2}{|c|}{$\%^{\mathrm{c}}$} \\
\hline & & & & & before & after \\
\hline 1 & Cyanidin 3-glucoside & 11.3 & 280,519 & $449[\mathrm{M}]^{+}, 287[\mathrm{M}-162]^{+}$ & 88.6 & 90.0 \\
\hline 2 & Cyanidin 3-rutinoside & 11.8 & 280,521 & $595[\mathrm{M}]^{+}, 449[\mathrm{M}-146]^{+}, 287[\mathrm{M}-146-162]^{+}$ & 6.7 & 6.4 \\
\hline 3 & Cyanidin 3-malonyl-glucoside & 14.5 & 280,522 & $535[\mathrm{M}]^{+}, 287[\mathrm{M}-248]^{+}$ & 1.5 & 0.9 \\
\hline 4 & Cyanidin 3-dioxalyl-glucoside & 15.1 & 280,523 & $593[\mathrm{M}]^{+}, 287[\mathrm{M}-306]^{+}$ & 3.2 & 2.7 \\
\hline
\end{tabular}

${ }^{a}$ Numbered according to Figure 2. ${ }^{b}$ Linear gradient of $5 \%$ formic acid/methanol. ${ }^{\mathrm{C}}$ Percentage of each peak area in relation to the total area, calculated at $520 \mathrm{~nm}$.

Effect of the gelation process on the anthocyanin composition

According to the chromatograms shown in Figure 2 and data from Table 1, the encapsulation process did not change the anthocyanin composition from the blackberry extracts.

Peaks 1 to 4 showed similar UV-Visible (UV-Vis) and mass spectra (MS) features to anthocyanins previously described in the literature. ${ }^{5,16,18}$ Cyanidin 3-glucoside (peak 1) showed the molecular ion $\left([\mathrm{M}]^{+}\right)$at $\mathrm{m} / z 449$ and the MS/MS fragment at $m / z, 287$, corresponding to the cyanidin moiety, resulted from the loss of a hexose. Cyanidin 3-rutinoside (peak 2) showed the $[\mathrm{M}]^{+}$at $\mathrm{m} / \mathrm{z}, 595$ and two mass fragments with 287 and $449 \mathrm{u}$, the first one corresponded to the cyanidin moiety due to the loss of rutinose $(308 \mathrm{u})$ and the fragment at $\mathrm{m} / \mathrm{z} 449$ resulted from the loss of a deoxyhexose [M$146]^{+}$. Different from other disaccharides, where the ionization did not cleave the glycosyl bond between the sugar unities, the $(1 \rightarrow 6)$-glycosyl bond between the rhamnose and the glucose moieties allowed free rotation and more accessibility to the gas used to produce fragmentation. ${ }^{25}$ This fragmentation pattern was already reported by De Rosso and Mercadante ${ }^{16}$ and $\mathrm{Wu}$ and Prior. ${ }^{5}$ The identification of both cyanidin 3 -glucoside and cyanidin 3-rutinoside was confirmed by co-elution with standards. The acylated anthocyanins (peaks 3 and 4) were tentatively identified as 3-malonyl-glucoside and 3-dioxalyl-glucoside of cyanidin, respectively, by the UVVis spectra, molecular ion and MS/MS fragments (Table 1). In addition, these anthocyanins were already found in blackberry extracts. ${ }^{3,5,26}$

\section{Characteristics of curdlan-anthocyanin capsules}

Regardless the different curdlan concentrations (4.3, 5.1 and 5.6\%), all capsules showed spherical form and multinucleated appearance (Figure 3). This multinuclear aspect is most probably due to hydrophobic interactions between the curdlan and soybean oil during the gum gelation under high temperature, creating hydrophobic patches with trapped oil molecules..$^{23,27}$

The use of different microscope objectives to register the capsule images (Figure 3 ) allowed the visualization of the rough wall, possible agglomerates and determination of capsule size distribution.

The variation of gum concentrations, within the range applied in this study had little effect on the size characteristics of curdlan-anthocyanin capsules. As shown in Figure 4, for all polymer concentrations, most capsules (between $83 \%$ and $88 \%$ ) showed diameter ranging from 0.3 to $0.8 \mathrm{~mm}$. In fact, the capsules mean size values (Table 2) 


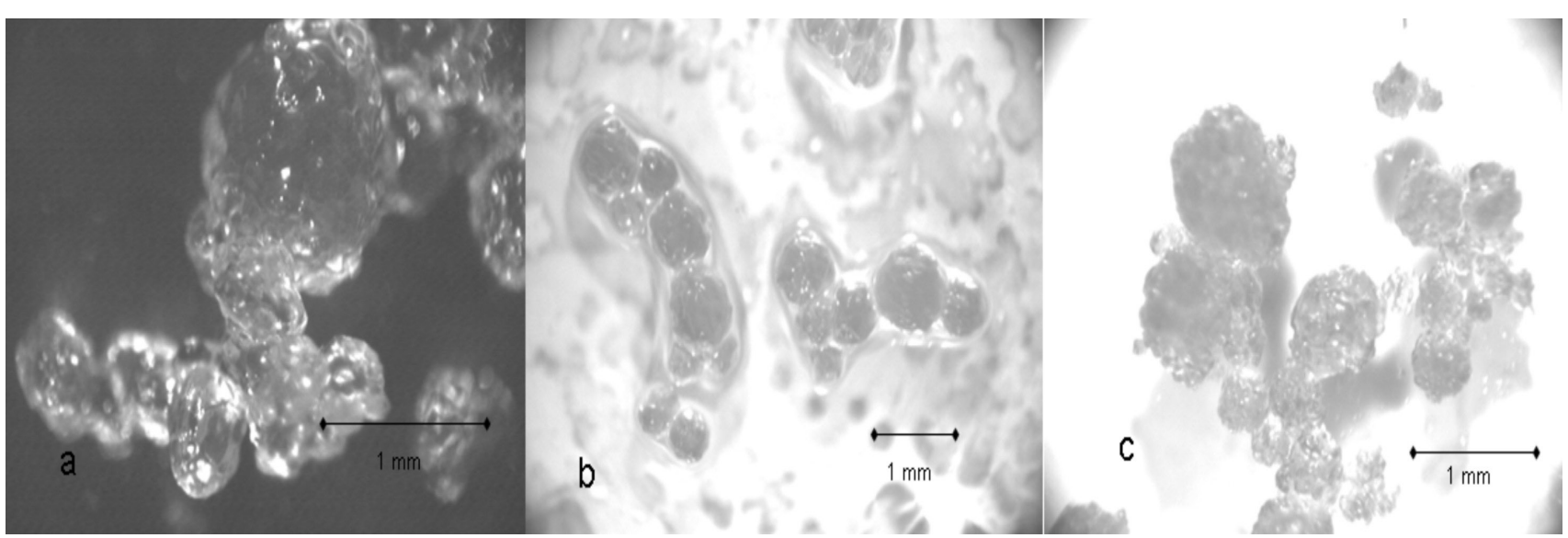

Figure 3. Stereo-microscope images obtained from curdlan-anthocyanin capsules made with (a) $4.3 \%$ (objective $3.2 \times$ ), (b) $5.1 \%$ (objective $1.6 \times$ ) and (c) $5.6 \%$ (objective $2.0 \times$ ) of curdlan.
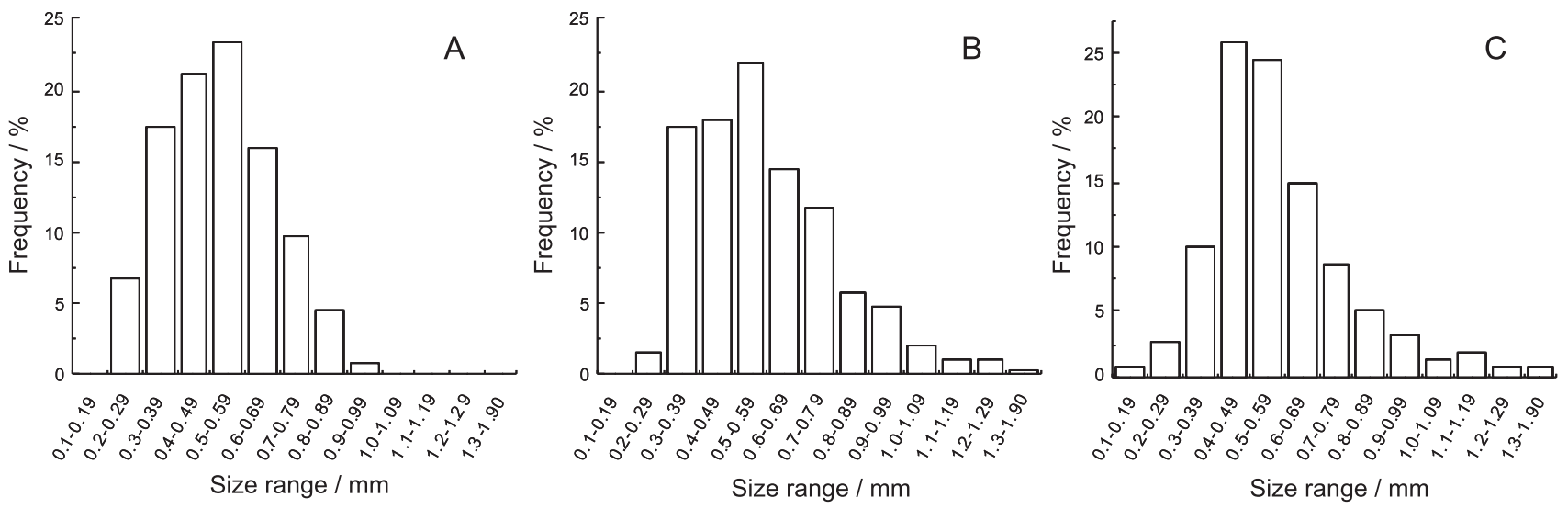

Figure 4. Size distribution of curdlan-anthocyanin capsules made with (A) $4.3 \%$, (B) $5.1 \%$ and (C) $5.6 \%$ of curdlan.

Table 2. Characteristics of curdlan-anthocyanin capsules

\begin{tabular}{lccc}
\hline Capsules $^{\mathrm{a}}$ & Mean size $^{\mathrm{b}}(\mathrm{mm})$ & Moisture $^{\mathrm{b}}(\%)$ & $\mathrm{EE}^{\mathrm{b}, \mathrm{c}}(\%)$ \\
\hline $4.3 \%_{\mathrm{m} / \mathrm{v}}$ & $0.52 \pm 0.16$ & $66.7 \pm 1.4$ & $80.3 \pm 0.1$ \\
$5.1 \%_{\mathrm{m} / \mathrm{v}}$ & $0.59 \pm 0.21$ & $78.7 \pm 1.4$ & $95.2 \pm 0.2$ \\
$5.6 \%_{\mathrm{m} / \mathrm{v}}$ & $0.58 \pm 0.22$ & $83.3 \pm 0.7$ & $96.7 \pm 0.2$ \\
\hline
\end{tabular}

aParticles classified according to the curdlan final concentration in solution; ${ }^{b}$ Average and standard deviation of triplicate analysis. ${ }^{\mathrm{c}} \mathrm{EE}$ : encapsulation efficiency calculated according to equation 1.

were similar for all curdlan concentrations, since all the other process conditions were kept constant.

On the other hand, the moisture of the capsules and encapsulation efficiency increased as curdlan concentration increased (Table 2). This result was in agreement with the fact that the highest water retention capacity of curdlan gel occur at gelation temperatures higher than $50-60{ }^{\circ} \mathrm{C}$, i.e. to form the high-set gel, and the trapped water is proportional to the amount of polysaccharide concentration. ${ }^{24}$

The encapsulation efficiency (Table 2) increased as curdlan gum concentration increased since with higher polysaccharide contents, the conversion from thermoreversible to thermo-irreversible gel is faster, due to strong hydrophobic interactions. ${ }^{24}$ This faster conversion probably increases the anthocyanin quantity retained into the capsules.

\section{Release of anthocyanins from the capsules}

As observed in the release profiles (Figure 5), the anthocyanins showed a strong burst effect in the first $10 \mathrm{~min}$, independently of the curdlan concentration in the capsules. In fact, the anthocyanins were completely released in $\mathrm{pH} 1.0$ buffer solution after $20 \mathrm{~min}$, except for the capsules with lower curdlan concentration, which showed $80-85 \%$ of released anthocyanins after $20 \mathrm{~min}$. This fact was not expected since the increase in curdlan concentration is expected to promote an increase on gel strength. ${ }^{24,27}$

The release curves were adjusted to first order exponential kinetic using the initial points of the experiment (from 0 to $60 \mathrm{~min}$; Figure 5), according to equation 2, where 


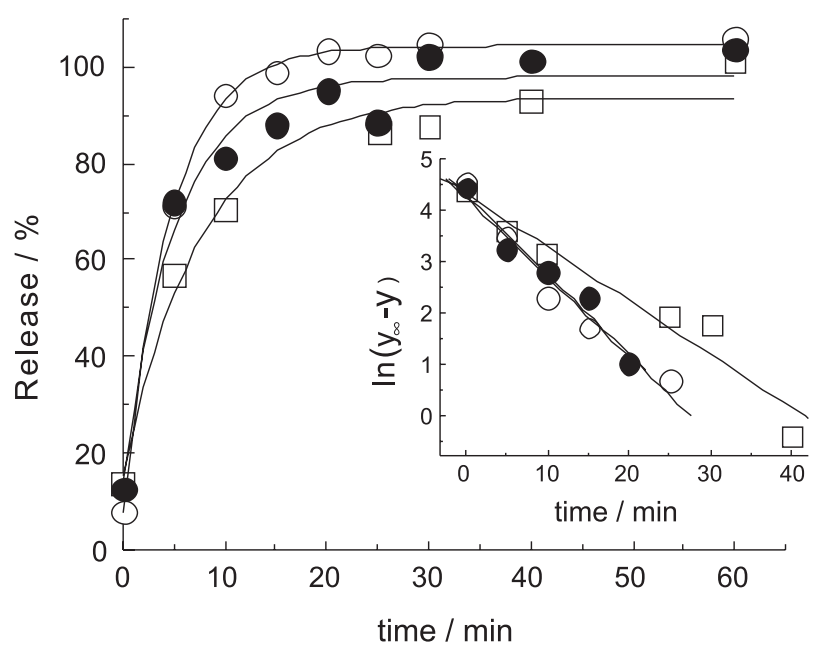

Figure 5. Release curves (first $60 \mathrm{~min}$ ) obtained for curdlan-anthocyanin capsules made with $(\square) 4.3 \%,(\bigcirc) 5.1 \%$ and $(-) 5.6 \%$ of curdlan. Inset: linear fit for $\ln \left(\mathrm{y}_{\infty}-\mathrm{y}\right) v s$. time.

$y=$ percent of release, $y_{\infty}=$ percent of release at infinite time, $A=y_{0}-y_{\infty}, y_{0}=$ percent of release at initial time, $x$ $=$ time, and $\mathrm{t}=$ half-life time.

$y=y_{\infty}+A \cdot e^{-x / t}$

The first order behavior of these release curves were confirmed by the linear graphics for plot of $\ln \left(\mathrm{y}_{\infty}-\mathrm{y}\right) v s$. time, shown in the inset of Figure 5, with $\mathrm{R}^{2}$ values higher than 0.964 (Table 3).

Table 3. First-order exponential parameters calculated for the release curves of anthocyanin capsules obtained with different curdlan concentrations

\begin{tabular}{lccc}
\hline Parameter & \multicolumn{3}{c}{ Curdlan concentration $(\mathrm{m} / \mathrm{v})$} \\
\cline { 2 - 4 } & $4.3 \%$ & $5.1 \%$ & $5.6 \%$ \\
\hline $\mathrm{y}_{\infty}^{\mathrm{a}}$ & $93.6 \pm 3.1$ & $104.3 \pm 0.7$ & $97.8 \pm 2.9$ \\
$\mathrm{~A}^{\mathrm{a}}$ & $-78.0 \pm 5.8$ & $-96.4 \pm 1.4$ & $-83.7 \pm 6.6$ \\
$\mathrm{t}^{\mathrm{a}} / \mathrm{min}$ & $7.8 \pm 1.4$ & $4.7 \pm 0.2$ & $5.2 \pm 1.0$ \\
$\mathrm{R}^{2}$ & 0.979 & 0.999 & 0.964 \\
$k^{\mathrm{a}} / \mathrm{min}^{-1}$ & $0.09 \pm 0.02$ & $0.15 \pm 0.01$ & $0.13 \pm 0.03$ \\
\hline
\end{tabular}

${ }^{a}$ Values are average \pm standard deviation of triplicate analysis.

The $k$ values ( $k=\ln 2 / t$ for first order kinetics) represent the observed rate constant of anthocyanin diffusion from capsules to bulk solution and surprisingly the diffusion rate for capsules with $4.3 \%$ of curdlan was slight lower than the diffusion rates for the capsules produced with higher curdlan amounts (Table 3). This fact could be related to the lowest moisture of the capsules with $4.3 \%$ of curdlan, indicating that anthocyanin diffusion was controlled by internal diffusion through the gel. That is, a lower quantity of water entrapped into the gel with the lowest curdlan content may turn more difficult the internal diffusion of the hydrosoluble core material since anthocyanins are highly soluble into the acidic aqueous medium.

Moreover, the fast release of anthocyanins from the capsules denoted that the crosslink three-dimensional net formed by triple-stranded or multiple helix chains in curdlan gelation ${ }^{27}$ was not entangled enough to obtain anthocyanin controlled release. However, the release of theophylline, a small hydrophilic molecule as anthocyanins, from curdlan jelly was proportional to the square-root of time. ${ }^{27}$ It is important to note that the methods used by these authors for the preparation of curdlan jelly and release assay were different from the methods used in the present study. Moreover, there is an important structural difference among anthocyanin and theophylline, the first one is a charged molecule, whilst theophylline is non-charged. In addition, since in curdlan high-set gel, the three strands of the triplex are linked together through triads of hydrogen bonds between hydroxyls at C-2, and the helices are linked together through hydrogen bonds involving hydroxyls located at C-4 and C-6, all hydroxyl oxygens participate in at least one hydrogen bond, ${ }^{28}$ thus the anthocyanins are probably not able to chemically link to the polysaccharide chains by hydrogen bonds.

\section{Conclusions}

In summary, capsules of anthocyanins in their colorful form were successfully obtained by thermal gelation of curdlan; however, the fast release of anthocyanins from the capsules was probably due to the absence of both chemical interaction between the pigment and the polysaccharide gel, and physical entrapment by the gel structure. Other studies are necessary in order to get controlled release of thermal encapsulated anthocyanins.

\section{Acknowledgments}

The authors thank the Brazilian Funding Agencies FAPESP (Fundação de Amparo à Pesquisa do Estado de São Paulo) and CAPES (Coordenação de Aperfeiçoamento de Pessoal de Nível Superior) for their financial support.

\section{References}

1. Antunes, L. E. C.; Ciência Rural 2002, 32, 151; Dai, J.; Patel, J. D.; Mumper, R. J.; J. Med. Food 2007, 10, 258; Seeram, N. P.; Adams, L. S.; Zhang, Y.; Lee, R.; Sand, D.; Scheuller, H. S.; Heber, D.; J. Agric. Food Chem. 2006, 54, 9329; Wang, S. Y.; Lin, H. S.; J. Agric. Food Chem. 2000, 48, 140. 
2. www.cpact.embrapa.br, accessed in November 2006.

3. Fan-Chiang, H. J.; Wrolstad, R. E.; J. Food Sci. 2005, 70, 198.

4. Stintzing, F. C.; Stintzing, A. S.; Carle, R.; Frei, B.; Wrolstad, R. E.; J. Agric. Food Chem. 2002, 50, 6172.

5. Wu, X.; Prior, R. L.; J. Agric. Food Chem. 2005, 53, 2589.

6. Benvenuti, S.; Pellati, F.; Melegari, M.; Bertelli, D.; J. Food Sci. 2004, 69, 164; Hager, T. J.; Howard, L. R.; Prior, R. L.; J. Agric. Food Chem. 2008, 56, 689; Hassimotto, N. M. A.; Mota, R. V.; Cordenunsi, B. R.; Lajolo, F. M.; Cienc. Tecnol. Aliment. 2008, 28, 702; Pantelidis, G. E.; Vasilakakis, M.; Manganaris, G. A.; Diamantidis, G. R.; Food Chem. 2007, 102, 777; Sellappan, S.; Akoh, C. C.; Krewer, G.; J. Agric. Food Chem. 2002, 50, 2432.

7. Mercadante, A. Z.; Bobbio, F. O. In Food Colorants: Chemical and Functional Properties; Socaciu, C., ed.; CRC Press: Boca Raton, 2008, ch. 4.3.

8. Maçanita, A. L.; Moreira, P. F.; Lima, J. C.; Quina, F. H.; Yihwa, C.; Vautier-Giongo, C.; J. Phys. Chem. A 2002, 106, 1248.

9. Kumar, M. N. V. R.; J. Pharm. Pharm. Sci. 2000, 3, 234.

10. Burey, P.; Bhandari, B. R.; Howes, T.; Gidley, M. J.; Crit Rev. Food Sci. Nutr. 2008, 48, 361; Alonso, F. O. M.; Antunes, O. A. C.; Oestreicher, E. G.; J. Braz. Chem. Soc. 2007, 18, 566.

11. Harada, T.; Misaki, A.; Saito, H.; Arch. Biochem. Biophys. 1968, 124, 292.

12. Zhang, H.; Nishinari, K.; Williams, M. A. K.; Foster, T. J.; Norton, I. T.; Int. J. Biol. Macromol. 2002, $30,7$.

13. Xiong, S.; Melton, L. D.; Easteal, A. J.; Siew, D.; J. Agric. Food Chem. 2006, 54, 6201.

14. Kohno, Y.; Kinoshita, R.; Ikoma, S.; Yoda, K.; Shibata, M.; Matsushima, R.; Tomita, Y.; Maeda, Y.; Kobayashi, K.; Appl. Clay Sci. 2009, 42, 519

15. Francis, F. J. In Anthocyanins as Food Colors; Markakis, P., ed.; Academic Press: London, 1982, ch. 5.
16. De Rosso, V. V.; Mercadante, A. Z.; J. Agric. Food Chem. 2007, 55,9135 .

17. Degenhardt, A.; Knapp, H.; Winterhalter, P.; J. Agric. Food Chem. 2000, 48, 338.

18. De Rosso, V. V.; Hillebrand, S.; Montilla, E. C.; Bobbio, F. O.; Winterhalter, P.; Mercadante, A. Z.; J. Food Compos. Anal. 2008, 21, 291.

19. Lee, J.; Durst, R. W.; Wrolstad, R. E.; J. AOAC Int. 2005, 88 , 1269.

20. McNamee, B. F.; O'Riorda, E. D.; O'Sullivan, M.; J. Agric. Food Chem. 2001, 49, 3385.

21. Jurd, L.; Asen, S.; Phytochemistry 1966, 5, 1263.

22. Gombotz, W. R.; Wee, S. F.; Adv. Drug Delivery Rev. 1998, 31 , 267.

23. Ikeda, S.; Shishido, Y.; J. Agric. Food Chem. 2005, 53, 786.

24. Funami, T.; Funami, M.; Yada, H.; Nakao, Y.; Food Hydrocolloids 1999, 13, 317.

25. Giusti, M. M.; Rodriguez-Saona, L. E.; Griffinm, D.; Wrolstad, R. E.; J. Agric. Food Chem. 1999, 47, 4657.

26. Stintzing, F. C.; Stintzing, A. S.; Carle, R.; Wrolstad, R. E.; J. Agric. Food Chem. 2002, 50, 396.

27. Hino, T.; Ishimoto, H.; Shimabayashi, S.; J. Pharm. Pharmacol. 2003, 55, 435.

28. Deslandes, Y.; Marchessault, R. H.; Sarko, A.; Macromolecules 1980, 13, 1466.

Received: May 29, 2009

Web Release Date: November 19, 2009

FAPESP helped in meeting the publication costs of this article. 